\title{
THÀNH LẬP BẢN ĐỒ TẦN SUẤT CANH TÁC LÚA KHU VỰC HUYỆN TIỀN HẢI, TỈNH THÁI BÌNH SỬ DỤNG TƯ LIỆ VIẼ̃N THÁM ĐA THỜI GIAN
}

\author{
NGUYẼ̃N THANH BÌNH, PHAM QUANG VINH, NGUYẼ̃N NGỌC THẤNG \\ Viện Địa lý - Viện Hàn lâm Khoa học và Công nghệ Việt Nam
}

\section{Tóm tắt:}

Tư liệu viễn thám đa thời gian (MODIS, Landsat ...) đã từ lâu chứng minh tính hiệu quả trong giám sát quá trình canh tác nông nghiệp. Nghiên cứu này nhằm phát triển một phương pháp giám sát quá trình canh tác lúa ở huyện Tiền Hải tỉnh Thái Bình sử dụng dữ liệu viễn thám Landsat. Nghiên cứu đã tiến hành xử lý dữ liệu vệ tinh Landsat từ tháng 1 năm 2008 đến tháng 11 năm 2016 (45 cảnh ảnh), sử dụng phương pháp cây phân loại (Decision tree). Quy trình phân loại được thực hiện trong bốn bước chính: (1) chiết tách và xử lý dữ liệu EVI, NDWI đa thời gian; (2) khoanh vùng khu vực canh tác lúa; (3) phân loại loại hình canh tác lúa; và (4) đánh giá độ chính xác. Độ chính xác tổng thể của quá trình phân loại là $77.3 \%$ và $80 \%$ tương ứng với các năm 2010 và 2015. Kết quả so sánh diện tích được phân loại từ ảnh vệ tinh và diện tích theo số liệu thống kê được đánh giá chưa cao. Đặc biệt khu vực lúa một vụ, có sự phân loại nhầm với cây trồng hàng năm khác và khu vực có cỏ. Nghiên cứu này đã chứng minh khả năng giám sát quá trình canh tác nông nghiệp bằng dữ liệu viễn thám Landsat.

\section{Mở đầu}

Dữ liệu viễn thám đã từ lâu được sử dụng trong việc thành lập các bản đồ canh tác nông nghiệp $[3,5,7,8,17]$, các vệ tỉnh quang học cung cấp dữ liệu cho phép thực hiện các công việc giám sát, như dữ liệu MODIS giúp dễ dàng phân biệt khu vực canh tác lúa với các cây trồng khác thông qua các chỉ số thực vật (NDVI, EVI, ...) và chỉ số nước NDWI. Dữ liệu Landsat với độ phân giải không gian cao hơn đã thể hiện tính ưu việt khi nghiên cứu các khu vực nhỏ. Trong nghiên cứu này, chúng tôi hướng tới chỉ sử dụng dữ liệu Landsat để thành lập bản đồ canh tác lúa.

Hai chỉ số thực vật được sử dụng phổ biến nhất hiện nay là: chỉ số khác biệt thực vật NDVI và chỉ số tăng cường thực vật $E V I$. Trong đó, EVI nhạy cảm hơn tại các vùng có sinh khối cao, được cải thiện để nâng khả năng giám sát thảm thực vật thông qua việc tách biệt các tín hiệu của tán lá với đất trống và không chịu nhiều ảnh hưởng của khí quyển [10]. Vì vậy, trong nghiên cứu này, $\mathrm{EVI}$ sẽ được chọn là chỉ số để nghiên cứu chu kỳ sinh trưởng của cây trồng nông nghiệp.

Mục tiêu chính của nghiên cứu là để phát triển một phương pháp thành lập bản đồ tần suất canh tác lúa ở cấp huyện sử dụng dữ liệu Landsat cho 2 năm (2010 và 2015). Khu vực lựa chọn là huyện Tiền Hải tỉnh Thái Bình.

\section{Phương pháp và tư liệu nghiên cứu}

\subsection{Khu vực nghiên cứu}

Tiền Hải là một huyện ven biển của tỉnh Thái Bình, giáp ranh với các huyện Thái

Ngày nhận bài: 28/12/2016, ngày chuyển phản biện: 21/02/2017, ngày chấp nhận phản biện: 20/03/2017, ngày chấp nhận đăng: 22/3/2017 
Thụy, Kiến Xương của tỉnh Thái Bình và huyện Giao Thủy của tỉnh Nam Định. Khu vực nghiên cứu có tổng diện tích khoảng 22.604 ha [1]. Với 35 xã và thị trấn, khu vực nghiên cứu được chia theo đơn vị hành chính xã như hình 1.

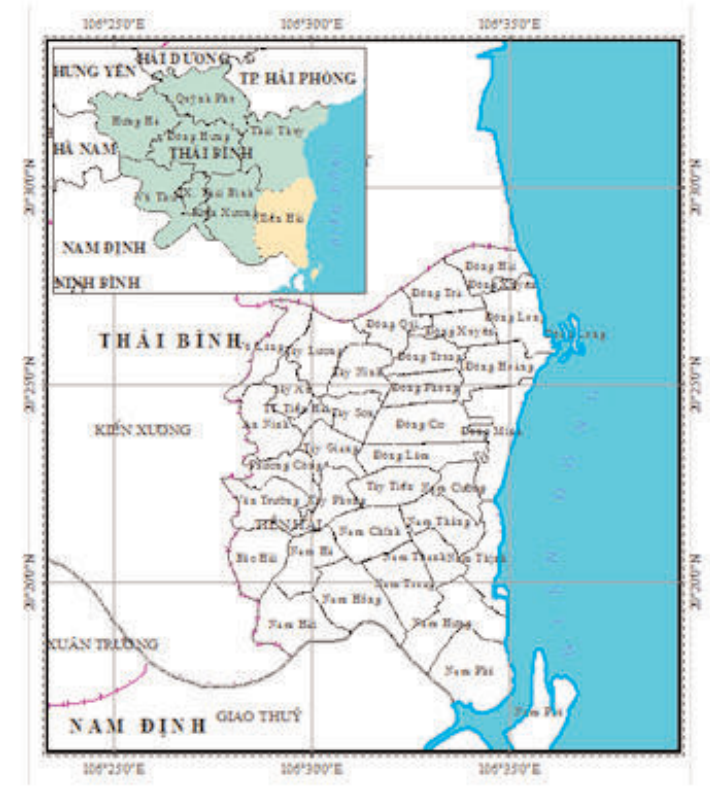

Hình 1: Vị trí khu vực nghiên cứu

\subsection{Phương pháp nghiên cứu}

Cây lúa có ba giai đoạn phát triển khác nhau: giai đoạn gieo cấy, thời gian sinh trưởng, và giai đoạn sau thu hoạch, mỗi giai đoạn sinh trưởng của cây lúa có một đặc trưng phổ riêng biệt và có thể được khai thác từ phân tích tư liệu viễn thám [7].

Các bước chính xử lý dữ liệu được miêu tả trong hình 2, bao gồm: (1) xây dựng chuỗi dữ liệu (EVI và NDWI) đa thời gian; (2) Khoanh vùng canh tác lúa; (3) phân loại; và (4) đánh giá độ chính xác. Việc phân tích những thay đổi trong lịch canh tác của địa phương cũng đã được kiểm tra.

a. Chiết tách, xử lý dữ liệu EVI và NDWI từ dữ liệu viễn thám đa thời gian

Dữ liệu NDWI sử dụng trong nghiên cứu này được tính theo công thức:

$$
\text { NDWI }=\frac{\text { Pnir }- \text { Pswir }}{\text { Pnir }+ \text { Pswir }}
$$

Dữ liệu $E V I$ được tính theo công thức sau đây

$$
\text { EVI }=2.5 * \frac{\text { Pnir }- \text { Pswir }}{\text { Pnir }+6 * \text { Pswir }-7.5 * \text { Pblue }+1}
$$

Trong đó: $P_{\text {nir }}$ là kênh phổ tương ứng với bức xạ hồng ngoại gần, $\mathrm{P}_{\text {blue }}$ là kênh phổ trong giải sóng màu xanh, $P_{\text {swir }}$ là kênh hồng ngoại giữa và $P_{\text {red }}$ là kênh phổ màu đỏ.

Để tạo chuỗi dữ liệu EVI và NDWI, trước tiên $E V I$ và $N D W I$ được tính cho mỗi ảnh Landsat. Dữ liệu sau đó được xếp chồng lên nhau thành một cảnh tổng hợp (23 cảnh cho năm 2010 và 22 cảnh cho năm 2015).

Sự thay đổi của các dữ liệu EVI bao gồm các tín hiệu "nhiễu" gây ra bởi mây, lỗi dữ liệu của Landsat 7 và sự thay đổi của hiện trạng bề mặt. Mức độ nhiễu lớn thường làm cho việc tính toán số lượng mùa vụ trở nên khó khăn. Để có thể phân tách các khu vực canh tác lúa và phân loại lúa, chuỗi dữ liệu $E V I$ cần phải được lọc bỏ nhiễu.

Để làm trơn dữ liệu và giảm nhiễu người ta dùng bộ lọc, bằng cách thay thế mỗi giá trị trong chuỗi $\mathrm{y}_{i}$ với $\mathrm{i}=1, \ldots, \mathrm{N}$ bằng một chuỗi tuyến tính các giá trị gần đó trong 1 cửa sổ lọc.

$$
\sum_{j=-n}^{n} c_{j} y_{i+j}
$$

Có nhiều thuật toán lọc cơ bản đó là: thuật toán Savitzky-Golay, Gaussian, và Logistics. Trong nghiên cứu này, chúng tôi lựa chọn thuật toán Savitzky-Golay [19]. (Xem hinh 2)

\section{b. Khoanh vùng khu vực canh tác lúa}

Nghiên cứu này dựa trên kết quả phân tích quá trình thay đổi các giá trị của chuỗi dữ liệu EVI và NWDI kết hợp với các thông 
số được xác định bởi Xiao et al. (2005); Xiao, et al. (2006) và kết quả nghiên cứu của Caitlin Kontgis và công sự đã áp dụng cho vùng Đồng bằng sông Cửu Long [2] để tách vùng trồng lúa khỏi các loại hình sử dụng đất khác. Không giống như các loại cây trồng khác, trong giai đoạn gieo cấy, ruộng lúa đang bị ngập nước, các giá trị của $E V I$ lúc này là rất thấp và chỉ số NDWI có thể được sử dụng để ghi lại giai đoạn sinh trưởng này vì thực vật phản ánh mạnh mẽ ở giải phổ hồng ngoại gần, trong khi nước hấp thụ cả cận hồng ngoại và hồng ngoại sóng ngắn [6]. Sau khi gieo hạt, lúa chuyển sang giai đoạn sinh trưởng, giai đoạn này có thể được nhận biết khi sử dụng NDWI kết hợp với $E V I$ vì giá trị $E V I$ tăng nhanh chóng trong thời gian này $[9,15]$. Giai đoạn bỏ hoang sau thu hoạch, đây là giai đoạn những cánh đồng lúa chủ yếu là đất trống hay bị ngập nước, khi đó các giá trị của EVI rất thấp [12], do đó chúng tôi nhận thấy rằng các khu vực có giá trị độ lệch tiêu chuẩn của NDWI và EVI cao sẽ là khu vực có khả năng cao trồng lúa. Hơn nữa để phân biệt khu vực canh tác lúa với các khu vực khác có thực vật phủ quanh năm (rừng, cây trồng lâu năm...), chúng tôi sử dụng giá trị EVI trung bình, vì các khu vực này có giá trị $E V I$ cao và ổn định trong cả năm. Do đó, diện tích trồng lúa được xác định khi thỏa mãn 3 điều kiện sau: có giá trị độ lệch tiêu chuẩn
NDWI cao, có giá trị độ lệch tiêu chuẩn EVI cao, và có giá trị EVI trung bình ở mức thấp.

\section{c. Phân loại cây trồng lúa}

Một chu kỳ sinh trưởng của cây lúa phải bao gồm đầy đủ 3 giai đoạn (gieo cấy, phát triển, thu hoạch) và phải nằm trong một khoảng thời gian cụ thể được xác định bằng lịch canh tác của địa phương. Đối với khu vực Tiền Hải, thông thường một năm có hai vụ canh tác lúa là vụ đông xuân và vụ mùa. Vụ đông xuân được canh tác từ cuối tháng hai đến đầu tháng sáu. Còn vụ mùa diễn ra từ cuối tháng bảy đến đầu tháng mười một. Khoảng thời gian giữa hai vụ không quá 80 ngày, và các giống lúa được canh tác tại đây có chu kỳ từ 120 đến 130 ngày.

Để phân biệt số lượng mùa vụ, đầu tiên chúng tôi chọn ra các vùng mẫu cho mỗi loại hình canh tác. Tiến hành phân tích sự thay đổi của các giá trị $E V I$ và xác định giá trị $E V I$ lớn nhất - gọi là đỉnh. Các vùng mẫu được lựa chọn dựa trên dữ liệu google earth, kết hợp với bản đồ sử dụng đất cho các năm tương ứng

Tiếp theo, xác định ngưỡng phù hợp để phân loại dựa trên giá trị của các đỉnh. Trong nghiên cứu này, giá trị ngưỡng được chọn dựa trên việc tham khảo các công trình nghiên cứu cho khu vực đồng bằng sông Cửu Long $[2,12]$ và thuật toán cây

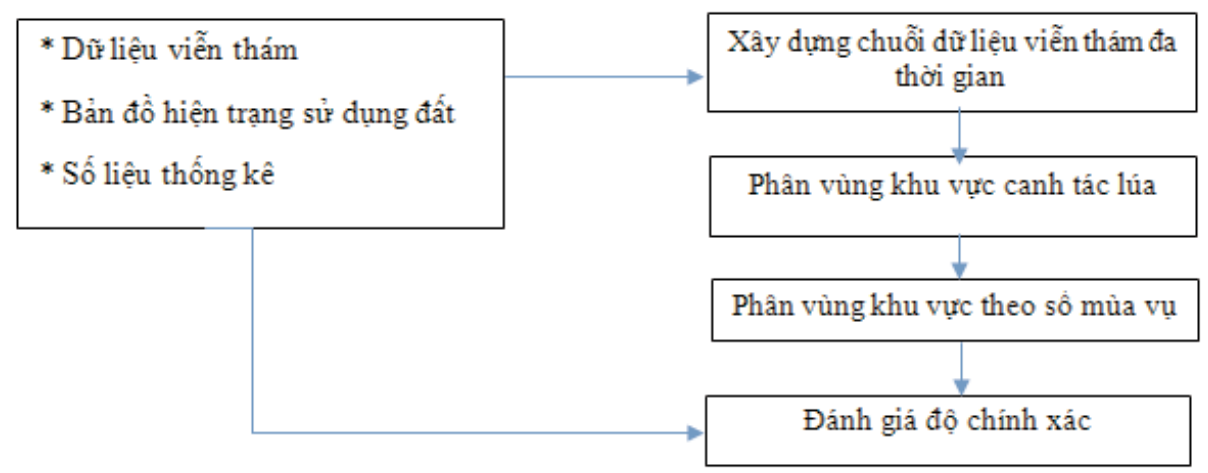

Hình 2: Quy trình thành lập bản đồ tần suất canh tác nông nghiệp cho huyện Tiền Hải tỉnh Thái Bình sử dụng dữ liệu Landsat 
phân loại (decision tree). Toàn bộ thuật toán cây phân loại được xây dựng trong phần mềm thống kê $R$ [19]. Thuật toán này sau khi được xây dựng trong $R$ cho các vùng mẫu đã được đưa vào chạy cho toàn bộ dữ liệu trong phần mềm ENVI.

\section{d. Đánh giá chính xác}

Độ chính xác của bản đồ phân loại đã được xác định bằng cách sử dụng ma trận đánh giá (confusion matrix) bao gồm sai số tổng thể và hệ số Kappa. Đối với mỗi lớp, 200 điểm ảnh được trích ra một cách ngẫu nhiên. Ngoài ra, các số liệu thống kê diện tích lúa của khu vực nghiên cứu các năm tương ứng cũng đã được sử dụng để đánh giá sự phù hợp của các kết quả phân loại.

\subsection{Tư liệu nghiên cứu}

\section{a. Dũ liệu vệ tinh}

Lúa trong khu vực được trồng trong chu kỳ một năm, với hai vụ (vụ Đông xuân từ tháng 2 đến tháng 6 và vụ Mùa từ tháng 7 đến tháng 11) xen kẽ các vụ mầu. Để nắm bắt những xu hướng này, chúng tôi sử dụng dữ liệu Landsat của một năm cho từng thời điểm nghiên cứu $(2010,2015)$, lấy hình ảnh bổ sung từ \pm 1 1-2 năm để lấp đầy tháng và mùa mà không có cảnh trong từng thời kỳ quan tâm (Hình 3). Sử dụng ảnh của nhiều năm cho phép cung cấp thêm các dữ liệu cho các khu vực bị mây che phủ, độ phân giải thời gian thấp và lỗi dữ liệu SLC-off của ảnh Landsat 7 . Trong nghiên cứu này, chúng tôi giả định rằng không có sự thay đổi về sử dụng đất chủ yếu ở các vùng trồng lúa trong những dữ liệu vệ tinh được sử dụng cho từng thời kỳ.

\section{b. Dữ liệu khác}

Bản đồ phụ trợ, bao gồm cả các bản đồ lớp phủ năm 2010 của huyện Tiền Hải (tỷ lệ: 1/125.000), niên giám thống kê huyện Tiền Hải năm 2010, 2015, ảnh Google Earth và các thông tin ghi nhận từ các báo cáo của địa phương. Các dữ liệu được thu thập để hỗ trợ quá trình phân tích dữ liệu và đánh giá độ chính xác của kết quả phân loại.

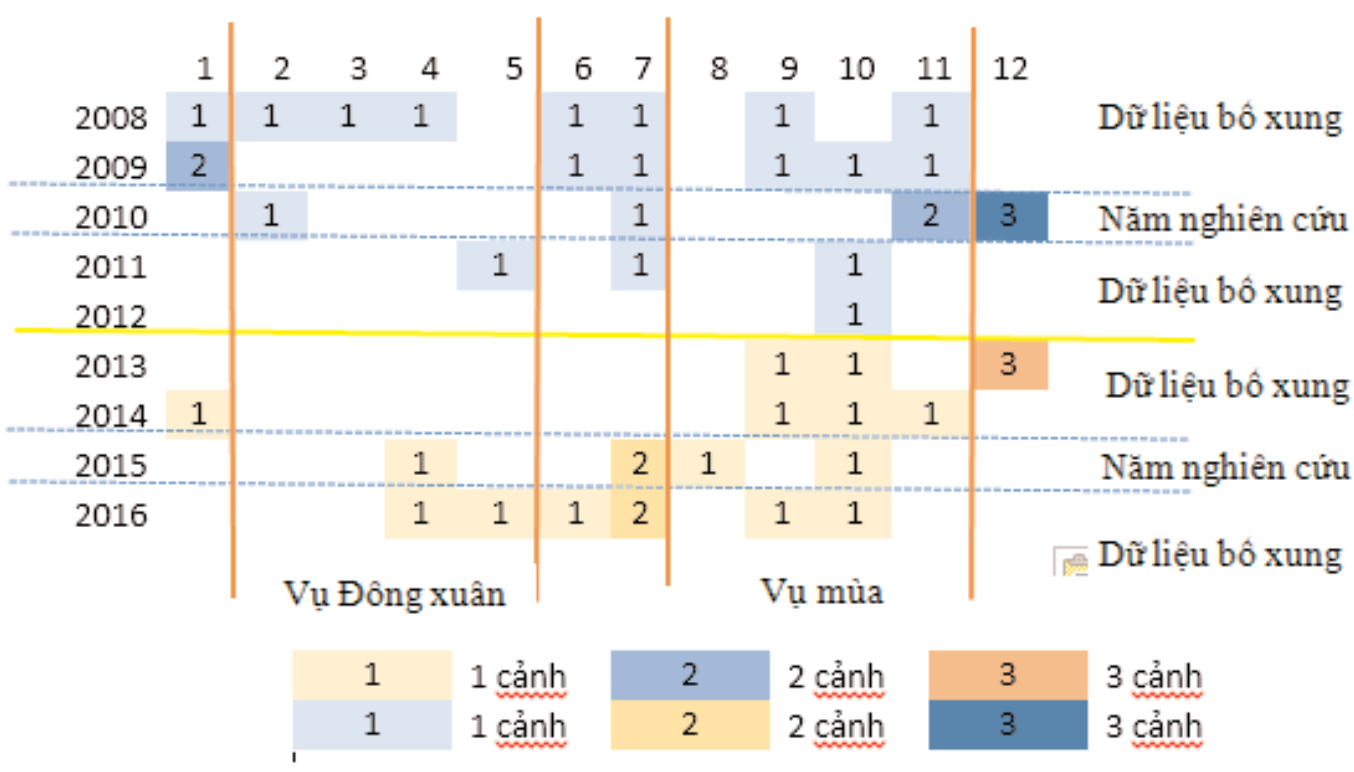

Hình 3: Số lượng ảnh vệ tinh khu vực nghiên cứu giai đoạn 2008 đến 2016 


\section{Kết quả và thảo luận}

\subsection{Phân tích chuỗi dữ liệu EVI đa thò̀i gian}

Quá trình phân tích và lọc được áp dụng cho mỗi điểm ảnh của chuỗi dữ liệu EVI. Các kết quả phân tích chuỗi dữ liệu $E V I$ được thể hiện trong hình 4 . Kết quả cho thấy sự thay đổi theo mùa của của các giá trị EVI trong giai đoạn nghiên cứu (năm 2010 và 2015). (Xem hình 4)

Dựa trên sự phân tích chuỗi dữ liệu EVI, có thể thấy giá trị $E V I$ có 2 đặc điểm 1) giá trị EVI tại các khu vực không canh tác lúa thấp và ổn định hơn so với các khu vực canh tác lúa; 2) giá trị trung bình của EVI cho toàn bộ thời gian nghiên cứu tại khu vực không canh tác lúa đều thấp hơn 0.05 . Đối với các khu vực có thảm phủ quanh năm (rừng, trang trại, vườn...) các giá trị $E V I$ đều lớn hơn 0.2 và tương đối ổn định trong toàn bộ thời gian nghiên cứu.

Đối với khu vực rừng có một vài thời điểm giá trị $E V I$ biến động lớn là do dữ liệu sử dụng trong nghiên cứu này không thống nhất trong một năm. Khu vực rừng của huyện Tiền Hải trong giai đoạn nghiên cứu biến động tương đối lớn.

\subsection{Bản đồ tần suất canh tác huyện Tiền Hải, tỉnh Thái Bình}

Kết quả phân tích các vùng mẫu đã xác định được giá trị ngưỡng là 0.35 . Do đó, nếu khu vực có duy nhất một đỉnh lớn hơn 0,35 rợ vào tháng tư đến tháng năm hoặc từ tháng chín đến tháng mười được phân loại là lúa một vụ (Hình 4d, 4e). Nếu vị trí có hai đỉnh lớn hơn 0,35 và những đỉnh đầu tiên và thứ hai, tương ứng, rợ vào giữa tháng tư-tháng năm và tháng chín - tháng mười được phân loại là lúa hai vụ (hình 4f).

Bản đồ tần suất canh tác lúa huyện Tiền Hải năm 2010 và 2015 được thể hiện trong hình 5 . Từ các bản đồ và số liệu thống kê của địa phương về các hoạt động canh tác lúa từ 2008 đến 2016 chỉ ra rằng hầu hết lúa được canh tác hai vụ ở Tiền Hải. Khu vực lúa một vụ phân bố dọc theo các con sông. Nguyên nhân xuất hiện các khu vực canh tác một vụ là do mưa bão gây ngập úng và người dân bỏ hoang ruộng không canh tác. (Xem hình 5)

Các số liệu thống kê diện tích lúa và những thay đổi diện tích cho mỗi hệ thống

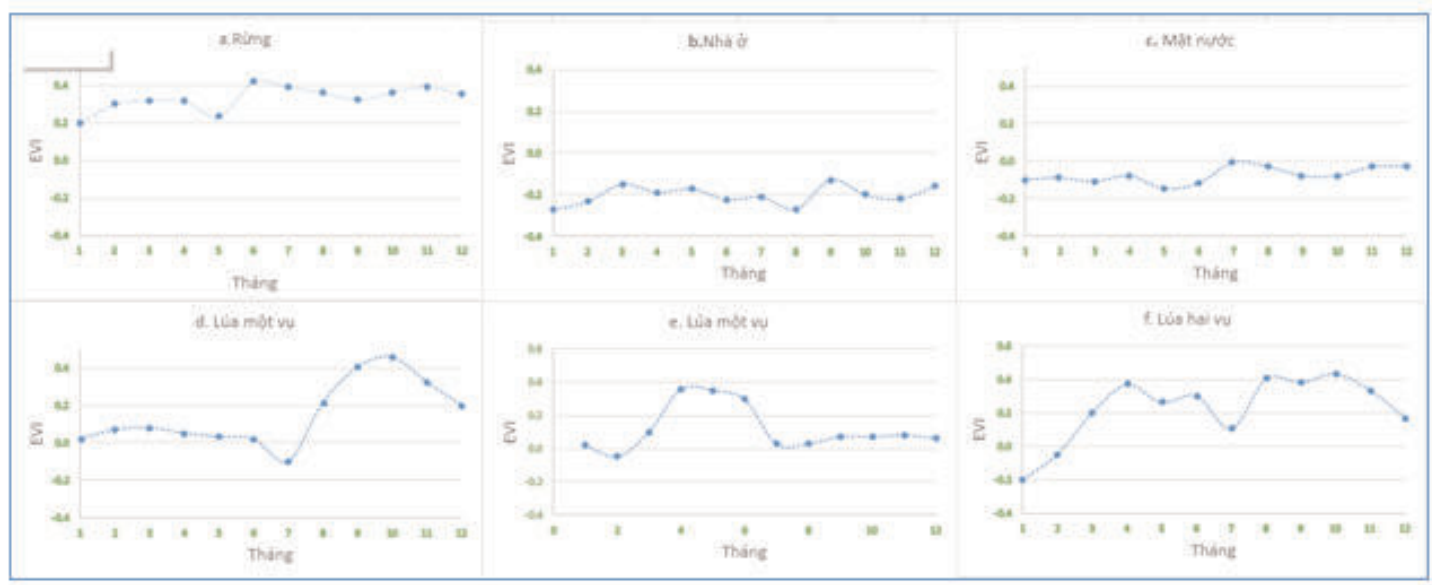

Hình 4: Chuỗi dữ liệu EVI (năm 2010 và 2015) hiển thị thông tin sử dụng để phân loại hệ thống canh tác lúa ở khu vực nghiên cứu cho các đối tượng: (a) rừng, (b) nhà ở, (c) mặt nước, $(d, e)$ lúa một vụ, và (f) lúa hai vụ 
canh tác trong 2 năm 2010 và 2015 được thể hiện trong bảng 1. Kết quả cho thấy, trong 5 năm từ 2010 đến 2015 tổng diện tích canh tác lúa biến động không lớn (diện tích canh tác lúa năm 2015 tăng 29 ha so với năm 2010). Sự tăng không đáng kể này là do phần lớn diện tích của huyện Tiền Hải đã

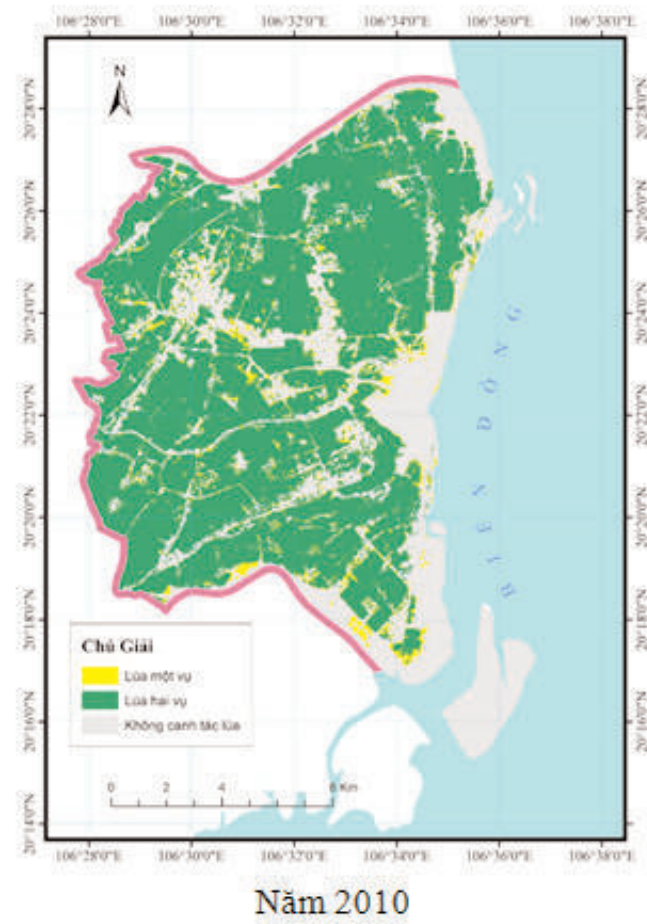

được sử dụng cho canh tác lúa từ trước năm 2010. Diện tích lúa hai vụ giảm từ 11004.81 ha năm 2010 xuống 10712.52 năm 2015. Sự giảm diện tích là do một phần diện tích nông nghiệp đã chuyển sang các mục đích khác như xây dựng nhà, làm trang trại...(Xem bảng 1)

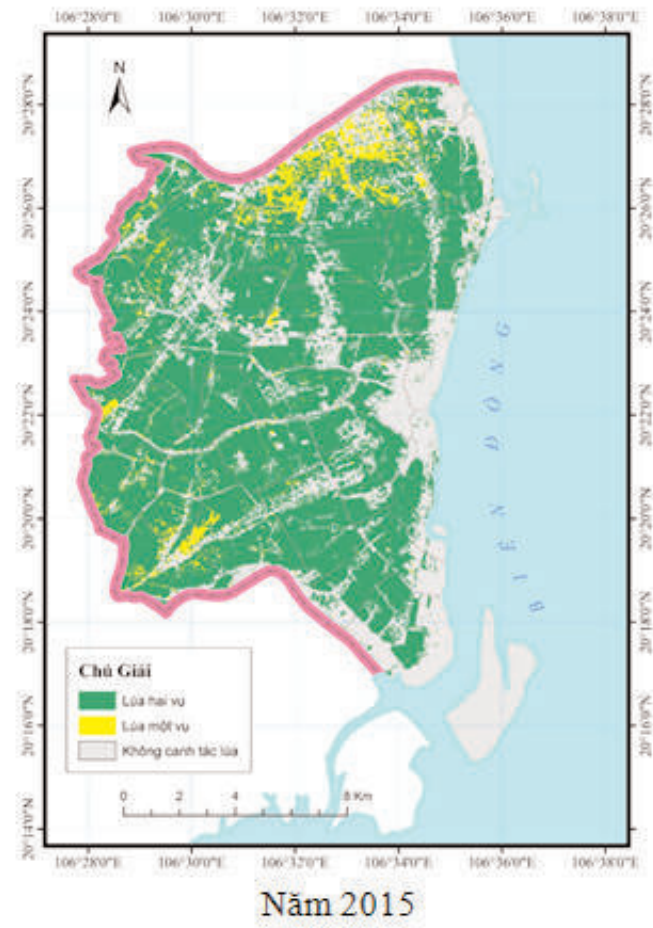

Hình 5: Bản đồ tần suất canh tác lúa huyện Tiền Hải năm 2010 và 2015

Bảng 1: Thống kê diện tích của hệ thống canh tác lúa các năm 2010 và 2015 của huyện Tiền Hải

\begin{tabular}{|c|c|c|c|c|c|c|}
\hline \multirow{2}{*}{ Năm } & \multicolumn{2}{|c|}{ Không canh tác lúa } & \multicolumn{2}{c|}{ Lúa một vụ } & \multicolumn{2}{c|}{ Lúa hai vụ } \\
\cline { 2 - 7 } & $\begin{array}{c}\text { Diện tích } \\
\text { (ha) }\end{array}$ & $\begin{array}{c}\text { Phần trăm } \\
(\%)\end{array}$ & $\begin{array}{c}\text { Diện tích } \\
\text { (ha) }\end{array}$ & $\begin{array}{c}\text { Phần trăm } \\
(\%)\end{array}$ & $\begin{array}{c}\text { Diện tích } \\
\text { (ha) }\end{array}$ & $\begin{array}{c}\text { Phần trăm } \\
\text { (\%) }\end{array}$ \\
\hline 2010 & 10946.7 & 48.4 & 653 & 2.9 & 11004.8 & 48.7 \\
\hline 2015 & 10975.7 & 48.6 & 916.3 & 4.1 & 10712.5 & 47.4 \\
\hline $\begin{array}{c}\text { Biến động } \\
(2015-2010)\end{array}$ & 29 & 0.1 & 263.3 & 1.2 & -292.3 & -1.3 \\
\hline
\end{tabular}




\section{3. Đánh giá độ chính xác kết quả phân loại}

Các bản đồ phân loại tần suất canh tác lúa năm 2010 và 2015 được so sánh với các dữ liệu tham chiếu mặt đất (bản đồ hiện trạng sử dụng đất và dữ liệu google earth). Độ chính xác tổng thể và hệ số Kappa tương ứng là $77.3 \%$ và 0.75 năm 2010; $80 \%$ và 0.81 đối với năm 2015. Kết quả phân loại khu vực canh tác lúa một vụ có độ chính xác chưa cao, vì đối tượng này chiếm diện tích nhỏ và phân phố rải rác dọc sông do đó dẽ dàng bị bỏ qua.

Nhìn chung, một số nguồn làm giảm độ chính xác kết quả phân loại: Các dữ liệu tham chiếu mặt đất chưa đồng nhất với dữ liệu vệ tinh; không sử dụng các số liệu tham chiếu thực tế ngoài thực địa; các cảnh ảnh vệ tinh không cùng một năm quan sát nên những khu vực có sự biến động về hiện trạng sử dụng đất sẽ gây ra sự nhầm lẫn khi phân loại; các dữ liệu ảnh Landsat vẫn có mây che phủ và lỗi ảnh Landsat 7 cũng là những nguyên nhân làm giảm độ chính xác kết quả phân loại.

Kết quả phân loại được so sánh với diện tích thống kê của địa phương (bảng 2). Kết quả so sánh diện tích được phân loại từ ảnh vệ tinh và diện tích theo số liệu thống kê được đánh giá chưa cao. Đặc biệt khu vực lúa một vụ, có sự phân loại nhầm với cây trồng hàng năm khác và các khu vực cỏ. (Xem bảng 2)

\section{Kết luận}

Trên cơ sở phân tích chuỗi dữ liệu EVI và NDWI được chiết suất từ dữ liệu Landsat, nghiên cứu bước đầu đã xây dựng thành công bản đồ tần suất canh tác lúa cho khu vực huyện Tiền Hải, tỉnh Thái Bình với độ chính xác tổng thể và hệ số Kappa tương ứng là $77.3 \%$ và 0.75 năm $2010 ; 80 \%$ và 0.81 đối với năm 2015.

Ngưỡng EVI để tách khu vực canh tác lúa với các đối tượng khác, bao gồm khu vực dân cư, mặt nước... có giá trị EVI dưới 0.05 và không thay đổi; đối với khu vực rừng và vườn giá trị EVI không thay đổi và trên 0.2 .

Đối với khu vực huyện Tiền Hải, việc phân loại lúa được thực hiện nếu một mẫu có duy nhất một đỉnh lớn hơn 0,35 rơi vào tháng tư đến tháng năm hoặc từ tháng chín đến tháng mười, sẽ được phân loại là lúa một vụ. Nếu mẫu có hai đỉnh lớn hơn 0,35 và những đỉnh đầu tiên và thứ hai, tương ứng, rơi vào giữa tháng tư, tháng năm và tháng chín - tháng mười, sẽ được phân loại là lúa hai vụ.

Kết quả cho thấy tư liệu Landsat có khả năng ứng dụng trong giám sát quá trình canh tác lúa, cũng như cung cấp các thông tin định lượng về khu vực trồng lúa, bao gồm 1) xác định vị trí, tính diện tích khu vực sử dụng cho trồng lúa; 2) giám sát chu kỳ canh tác hàng năm.

Bảng 2: Đánh giá độ chính xác phân loại với diện tích thực tế

\begin{tabular}{|c|c|c|c|c|}
\hline & \multicolumn{2}{|c|}{ Kết quả phân loại } & \multicolumn{2}{c|}{ Thực tế } \\
\hline & 2010 & 2015 & 2010 & 2015 \\
\hline Tổng diện tích canh tác lúa & 11657.81 & 11628.79 & 10730 & 10400 \\
\hline Lúa một vụ & 653 & 916.27 & 30 & 0 \\
\hline Lúa hai vụ & 11004.81 & 10712.52 & 10700 & 10400 \\
\hline
\end{tabular}


Sử dụng tính chất thay đổi cường độ EVI kết hợp với thuật toán cây phân loại (decision tree), nghiên cứu có thể khắc phục những hạn chế do thiếu dữ liệu do mây, độ phân giải thời gian thấp, và lỗi SLC-off của dữ liệu Landsat 7 . Tuy nhiên, trong nghiên cứu này chưa sử dụng các dữ liệu khảo sát thực địa nên độ chính xác kết quả phân loại chưa cao.

Để nâng cao độ chính kết quả phân loại cần kết hợp với các dữ liệu vệ tinh khác (như MODIS, EVISAT ASA...), đặc biệt các số liệu khảo sát thực địa đóng vai trò quan trọng giúp tăng cường độ chính xác phân loại. $\bigcirc$

\section{Tài liệu tham khảo}

[1]. Báo cáo đề tài cơ sở phòng Sinh thái Cảnh quan, 2014. "Sinh thái cảnh quan ứng dụng định hướng phát triển bền vững kinh tế xã hội huyện Tiền Hải”.

[2]. Caitlin Kontgis, et al (2015). Mapping rice paddy extent and intensification in the Vietnamese Mekong River Delta with dense time stacks of Landsat data. Remote sensing of Enviroment.

[3]. Frolking, Steve, et al. "Combining remote sensing and ground census data to develop new maps of the distribution of rice agriculture in China." Global Biogeochemical Cycles 16.4 (2002): 38-1.

[4]. Huke, R., \& Huke, E. (1997). Rice area by type of culture: South, Southeast, and East Asia. Areview and updated data base. International Rice Research Institute.

[5]. Knox, J., Matthews, R., \&
Wassmann, R. (2000). Using a crop/soil simulation model andGIS techniques to assess methane emissions from rice fields in Asia. III. Databases.

[6]. Gao, B. (1996). NDWI - A normalized difference water index for remote sensing ofvegetation liquid water from space. Remote Sensing of Environment, 58, 257266.

[7]. Le Toan, T., Ribbes, F., Wang, L., Floury, N., \& Ding, K. (1997). Rice crop mapping and mon-itoring using ERS-1 data based on experiment and modeling results. IEEE Transactionson Geoscience and Remote Sensing, 35(1), 41-56.

[8]. Liew, S.C., Kam, S., \& Tuong, T. (1998). Application of multitemporal ERS-2 synthetic ap-erture radar in delineating rice cropping systems in the Mekong River Delta, Vietnam. IEEE Transactions on Geoscience and Remote Sensing, 36(5), 1412-1420.

[9]. Liu, H.Q., \& Huete, A. (1995). A feedback based modification of the NDVI to minimize can-opy background and atmospheric noise. IEEE Transactions on Geoscience and RemoteSensing, 33(2), 457-465.

[10]. MODIS Vegetation Index User's Guide (MOD13 Series)

[11]. Nutrient Cycling in Agroecosystems, 58, 179-199.

[12]. Nguyen Thanh Son (2014). A phenology based classification of time series MODIS data for rice crop monitoring in Mekong Delta, Vietnam. Remote 
Sensing.2014, 6, 135-156.

[13]. Qiu, Jianjun, et al. "Mapping SingleDouble-, and Triple-crop Agriculture in China at $0.5^{\circ} \times 0.5^{\circ}$ by Combining Countyscale Census Data with a Remote Sensingderived Land Cover Map" Geocarto International 18.2 (2003): 3-13.

[14]. Williams, D.L., Goward, \& Arvidson, T. (2006). Landsat: Yesterday, today, and tomorrow.Photogrammetric Engineering and Remote Sensing, 72(10), 1171-1178.

[15]. Xiao, X., Boles, S., Frolking, S., Li, C., Babu, J.Y., Salas, W., \& Moore, B. (2006). Mapping paddy rice agriculture in South and Southeast Asia using multi-tem- poral MODIS im-ages. Remote Sensing of Environment, 100(1), 95-113.

[16]. Salas, S.L.; Hille, E.; Etgen, G.J. Calculus: One and Several Variables, 10th ed.; Wiley: Hoboken, NJ, USA, 2007.

[17]. Yang, S., Shen, S., Li, B., Le Toan, T., \& He, W. (2008). Rice mapping and monitoring usingENVISAT ASAR data. IEEE Geoscience and Remote Sensing Letters, 5(1), 108-112.

[18]. Nguyễn Văn Tuấn, 2014. Phân tích dữ liệu với $R$. Nhà xuất bản tổng hợp Hồ Chí Minh.

[19]. TIMESAT 3.2 software manual. $O$

\section{Summary}

Using multi-time remote sensing data to establish a map of the frequency of rice cultivation in Tien Hai district, Thai Binh province

Nguyen Thanh Binh, Pham Quang Vinh, Nguyen Ngoc Thang

Institute of Geography, Vietnam Academy of Science and Technology

Time series observations from the Landsat, MODIS... have provided useful datasets for identifying and monitoring agricultural processes. This study aims to develop a method monitoring the rice cropping systems in Tien Hai district, Thai Binh province using Landsat data. This study processed Landsat satellite data from January 2008 to November 2016 (45 scenes), and using the decision tree method. Classification process is performed in four main steps: (1) extraction and processing EVI, NDWI times series data; (2) mapping paddy extent; (3) mapping rice cycles; and (4) accuracy assessment. The overall accuracy of the classification was $77.3 \%$ and $80 \%$ respectively for 2010 and 2015 . The results by comparisons between Landsat-derived rice area and rice area statistics have not been evaluated high. This study has demonstrated the ability to monitor the process of rice cropping by Landsat data. $O$ 